\title{
Information file on compilers, tools, books, courses, tutorials, and the standard for the Fortran language and its derivatives 1
}

Version of 20 May 1999 (the penultimate year of the millennium)

\section{Mike Metcalf}

E-mail:michaelmetcalf@compuserve.com

\section{What's new?}

Since 20 April:

- Update Cray and SGI entries to Forran 95.

- Update Lahey's entry.

- Update Compaq e-addresses.

- Add Alan Miller's source form converter.

\section{Since 23 March:}

- Add "The DIGITAL Visual Fortran Programmer's Guide".

- Add Fortran 95 standard electronic ordering information.

- Update Compaq (Digital) entry for Linux.

Since 22 February:

- Update Wagener's book entry.

- Update Sun's entry.

- Delete Meissner's e-book.

- Add advice on dowloading Dubois's lecture notes.

- Replace IBM's entry - for Fortran 95 compliance etc.

- Replace Fujitsu's entry - for Fortran 95 compliance etc.

- Add Lahey/Fujitsu version of f90gl.

\footnotetext{
${ }^{1}$ This information is compiled on a "best-effort" basis and is without prejudice. It may be freely copied and disseminated. Corrections and additions are solicited. Additional information on Fortran products is available on the World Wide Web at the URLs http://www.fortran.com/fortran and http://www.fortranlib.com/.
}

\section{Where can I obtain a Fortran compiler?}

- Absoft sells its native version of Cray's CF90 for the Power Macintosh. It also has, among others, "Pro Fortran v6.0 for Windows", a complete workbench for PC users (sales@absoft.com or http://www.absoft.com). A parallelizing version for PCs and a Linux/x86 version are available.

- ACE of Holland provides 990 and HPF for Parsytec PowerPC-based machines (marco@ace.nl, http://www.ace.nl/).

- Apogee's 990 compiler is highly optimized for SPARC architectures (sales@ apogee.com or http://www.apogee.com).

- Compaq has Digital Fortran, an optimizing compiler for Digital UNIX Alpha systems that includes both HPF and directed decomposition directives for SMPs (parallel execution of HPF programs requires an optional companion product, the Parallel Software Environment), and Digital Fortran for OpenVMS Alpha (supports HPF syntax). These include all features in Fortran 95. For Windows NT (Intel, Alpha) and Windows 95 (Intel) there is Digital Visual Fortran (95), which includes Developer Studio from Microsoft. Compaq is also porting its Tru64 UNIX Alpha Fortran compiler along with the associated runtime libraries to Linux (Alpha) later in 1999. Contact fortran@compaq.com or http://www.compaq.com/fortran.

- Cray Research has a fully-optimizing, native Fortran 95 compiler that is being marketed by them for the CRAY J90, C90, T90, T3E and SV1 systems. It supports automatic parallization and OpenMP. In addition, Cray resells PGI's HPF compiler, for these same systems 
(http://www.cray.com/products/software/pe/cf90. html and hpf.html).

- EPC has optimizing, native compilers for Windows NT, x86, Sun, RS/6000, SGI and MIPS (http://www.epc.co.uk, info@epc.com, support@epc.co.uk). HPF is available. In Japan, contact SofTek Systems, Inc. (see below).

- Fujitsu has a Fortran 95 compiler for the platforms Solaris 2.3 or later and Windows NT/95/98, and highly optimized, native Fortran 90 compilers, Fortran90/VP and Fortran90/VPP, for the Fujitsu VPP series. Contact: rdsoft@fujitsu.co.uk or http://www.fujitsu.co.uk/new_devtools.htm.

- HP has collaborated with EPC to produce an optimizing compiler for HP-UX and SPP-UX platforms. See http://www.hp.com/go/hpfortran.

- IBM has an optimizing, native compiler for the $\mathrm{RS} / 6000$, xlf90. HPF is available too. See http://www.software.ibm.com/ad/fortran/xlfortran.

- IBM XL Fortran for AIX Version 6.1 supports the Fortran 95 standard. XLF is a highly optimized, native compiler designed to exploit the RS/6000 symmetric multi-processing (SMP) architecture as well as providing support for 64-bit pointers and addressability for serial and SMP codes. XLF V6.1 provides additional support for the OpenMP Fortran API, exploits the new IBM POWER3 architecture, and provides a technical preview of the new IBM Distributed Debugger. For more information: http://www.software.ibm.com/ad/fortran.

- Imagine1 Inc offers $F$, the subset language for Unix, Windows and Macintosh PowerPC, some in highly optimizing versions. They hope F will be the true stepping stone to HPF and at the same time replace Basic, Pascal and $\mathrm{C}$ for teaching purposes. The version for Linux/x 86 is free. See http://www.imagine1.com/imagine 1 and the book section below.

- Lahey/Fujitsu Fortran 95 is produced by the Lahey/Fujitsu alliance. LF95 is available in three configurations: LF95 Express, LF95 Standard, and LF95 PRO. All three configurations feature: VAX, IBM, and POSIX language extensions, Visual C++, Visual Basic, and Delphi compatibility, Y2K runtime checking, etc. The Standard system includes a Fortran-smart Windows editor, a debugger, an AUTOMAKE make utility, and an enhanced Winteracter Starter kit for creating true Windows programs with Fortran, and a Coverage Analysis Tool that detects unexecuted code and performs range of operation checking. The PRO system includes Fujitsu's Visual Analyzer that graphically displays the call structure and logic flow of Fortran source code (sales@lahey.com or http://www.lahey.com). There is also elf90, a subset language without old features like storage association that is designed for teaching, and is very cheap. It can be downloaded free from the Web site.

- Microway NDP Fortran 90 for 386/486 and Pentium is available (nina@microway.com). In Japan, contact SofTek Systems, Inc. (see below).

- NAG provides a compiler for most unix platforms, VMS and PCs (including Linux/x86 and Alpha). This was the first f90 compiler, in 1991. The unix and Linux ports have now been updated to Fortran 95. An optimizing version produced in collaboration with ACE (see above) for Suns is available. The NAGWare f90 Tools are a suite of Fortran 90 tools that, among other things, perform F77 to 190 conversion (infodesk@ nag.com, infodesk@nag.co.uk or http://www.nag.co.uk/).

- NA Software supplies Fortran 90 Plus on PCs (including Windows 95 and Linux/x86), Sparc, and T800 transputers. There is a cheap student version available. They also supply an F77 to f90 syntax convertor, LOFT90, and as well as HPF (http://www.nasoftware.co.uk/home.html).

- NEC has released a native, optimizing Fortran90 compiler, FORTRAN90/SX, with an automatic vectorization and parallelization capability, for its supercomputer $\mathrm{SX}$ series (sX-4@sxsmd.ho.nec.co.jp).

- PSR's VAST/f90 compiler for unix, VMS and Convex includes a vectorizer. PSR supplies VAST/77to90, to convert FORTRAN 77 programs into Fortran 90 syntax, as well as VAST/ HPF (info@psrv.com or http://www.psrv.com/). An f90/95/HPF compiler for linux/x 86 is free for personal use.

- PGI has a Fortran 90/HPF compiler for SGI, IBM SP2, HP/Convex, and Sun Ultra, as well as a native $\mathrm{F} 90 / \mathrm{HPF}$ compiler for Intel-based Linux/Solaris86/NT workstations and servers. The latter supports auto-parallelization, native OpenMP parallelization, and HPF parallelization (sales@pgroup.com or http://www.pgroup.com).

- Salford Software markets a Fortran 95 compiler for PCs, including Windows 95 and NT. A cheap student version is available: http://www. salford.co.uk/ or sales@salford-software.com or http://www.fortran.com/fortran/Salford. In Japan, contact SofTek Systems, Inc. (see below). 
- SGI has the MIPSpro Fortran 95 compiler (which now uses the Cray front end) available for all SGI IRIX systems. It can be configured with an optional Auto Parallelizing Option (APO) product to do automatic parallelization of Fortran code. It supports OpenMP (http://www.sgi.com/Products/ DevMagic/products/fortran.html).

- SofTech has a licence to sell its own versions of DEC's HPF/f90 compiler.

- SofTek Systems, Inc. is a provider of a wide variety of HPF compilers, tools, and technical expertise. See either info@softek.co.jp or http://www.softek.co.jp. Tel.: +81 33412 6008, Fax: +8133412 7990 .

- Sun has an f90 product, Sun Performance WorkShop Fortran 5.0 (http://www.sun.com/workshop/ fortran or tel. 1-800-SUNSOFT). For Sun's HPF, based on Thinking Machine's "GlobalWorks", see http://www.sun.com/hpc. Details of Sun's public-domain Fortran preprocessor are available at http://www.sun.com/workshop/fortran/wp-fpp/.

\section{Other useful products}

- Bradly Associates supplies the GINO and GINOMENU range of GUI and Graphics libraries for Win32, Unix and OpenVMS with an F90 binding. More information at www.bradassoc.co. uk.

- I.S.S. supplies Winteracter, a Win32 Fortran 90 user interface and graphics development tool. See http://www.demon.co.uk/issltd/.

- FORCHECK is a static analyzer for Fortran programs. It analyses both the individual program units and the whole program. It optionally verifies the syntax for conformance to the Fortran 90 standard, and provides warnings on undefined and unreferenced syntax items, inconsistent argument lists, and much more. FORCHECK generates documentation, such as cross-reference tables. See http://www.medfac.leidenuniv.nl/forcheck.

- HPF is available not only as listed above, but also on the definitive list of sites to be found at www.ac.upc.es/HPFSurvey. See also http://www.crpc.rice.edu/HPFF.

- A source form convertor, convert.f90, is obtainable by ftp from ftp.numerical.rl.ac.uk in the directory /pub/MandR. Latest version is 1.5.

- Another is Alan Miller's to_f90.f90 at http:// www.ozemail.com.au/milleraj.
- A 2- and 3-D OpenGL graphics interface, f90gl, for Unix and Windows $95 / \mathrm{NT}$, is obtainable at http://math.nist.gov/f90gl. Latest version is 1.1. A version compatible with Lahey/Fujitsu Fortran 95 (LF95) and Lahey Fortran 90 (LF90) is available at www.lahey.com/support/SetupF90gl.exe.

- A free set of wrapper routines to call a subset of Xlib routines from Fortran 90 is available from Garnatz and Grovender, Inc.: gginc@winternet. com, http://www.winternet.com/gginc/, or ftp.winternet.com/users/gginc.

- NAG (see above) and IMSL (now Visual Numerics, mktg@houston.vni.com) offer f90 versions of their maths libraries that take full advantage of the language's library building capabilities.

- An 190 mode is included in the official Emacs distribution (GNU Emacs-19.28/XEmacs-19.13 or later).

- For make files, a perl5 script, which behaves like an X11 makedepend program (it edits an existing Makefile) and recursively searches include files for more dependencies, is available from Kate Hedstrom: ftp://ahab.rutgers.edu/pub/perl/ sfmakedepend, http://marine.rutgers.edu/po/ perl.html. For a makemake perl script: http://www.fortran.com/fortran/makemake.html.

- FORESYS (FORtran Engineering SYStem) is an integrated set of tools designed for engineers in charge of developing, maintaining and upgrading programs written in Fortran. It is suited for, among other things, migrating applications from Fortran 77 to Fortran 90. See Simulog below.

- Polyhedron Software's plusFORT Version 6.0 has comprehensive facilities for translation of Fortran 77 and VAX Fortran to Fortran 90. A new Windows front-end is available for the NT version. A major feature is AUTOMAKE, which automatically detects Fortran 90 module dependencies. Sue@polyhdrn.demon.co.uk, http://www. polyhedron.co.uk/.

- A F90 source for a f90split utility is at ftp://ftp. ifremer.fr/ifremer/ditigo/fortran90/f90split.f90.gz. See also http://www.ifremer.fr/ditigo/molagnon/ fortran90/ and ftp://ftp.ifremer.fr/ifremer/ditigo/ fortran90/moware-1.0.tar.gz to get an F90 to PostScript list program and an F90 aware preprocessor similar to cpp, but with pretty-printing for the pre-processed code.

- Fortran90-lint, for Fortran 90 program analysis, also other tools, from http://www.iptweb.com/ tools/stprod/flint/flint90.html. 
- The C2F.ZIP file is available via ftp://members. aol.com/ DaveGemini/TEST. It contains C2F.EXE, a C=>F90 "hands-off" translator program for Win95/NT.

- Some coding and style guidelines have been developed by the European meteorologists: http:// www.meto.gov.uk/sec5/NWP/ NWP_F90Standards.html.

- f90SQL offers a convenient and familiar way to directly read and write data from your Fortran programs to many applications formats. See info about the library at http://www.canaimasoft.com/ f90sql.

\section{What books are available?}

$(*)$ is from stock at www.amazon.com.

\section{English:}

- Advanced Scientific Computing - Wille, Wiley, 1995, ISBN 0-471-95383-0.

- Atlas for Computing Mathematical Functions... in Fortran 90 and Mathematica - Thompson, Wiley, 1997, 0-471-18171-4. (*)

- Contemporary Computing for Technical Engineers and Scientists: using Fortran 90 and spreadsheets - Forsythe, PWS, 1997, 0-534-93139-1. $(*)$

- Essential Fortran 90 and 95 - Meissner, Unicomp, 1997, ISBN 0-9640135-3-3.

- Fortran 90 - Meissner, PWS Kent, Boston, 1995, ISBN 0-534-93372-6. (*)

- Fortran 90 - Huddleston, Exchange Publ. Div., Buffalo, NY, 1996, ISBN 0-945261-07-1.

- Fortran 90 and Engineering Computation - Schick and Silverman, John Wiley, 1994, ISBN 0-47158512-2. (*)

- Fortran 90, A Reference Guide - Chamberland, Prentice Hall PTR, 1995, ISBN 0-13-397332-8. $(*)$

- Fortran 90 Concise Reference - Wagener, Absoft, 1998, ISBN 0-9670066-0-0. (*)

- Fortran 90/95 Explained - Metcalf and Reid, Oxford University Press, 1996, ISBN 0-19-8518889 , about $\$ 33$. This book is a complete, audited description of the Fortran 90 and Fortran 95 languages in a more readable style than the standards themselves. It incorporates all J3 and WG5's interpretations and has a complete chapter on Fortran 95. It has seven Appendices, in- cluding an extended example program that is available by ftp and solutions to exercises. For US orders: www.oup-usa.org or toll free +1800 451 7556; in the UK: www.oup.co.uk. There are f90 versions in French, Japanese and Russian (see below). (*)

- Fortran 90 for Engineers and Scientists - Nyhoff and Leestma, Prentice Hall, 1996, ISBN 013-519729-5. An "Introduction to..." also exists: 1996, ISBN 0-13-505215-7. (*)

- Fortran 90 for Scientists and Engineers - Brian D. Hahn, Edward Arnold, 1994, ISBN 0-34060034-9.

- Fortran 90/95 for Scientists and Engineers Chapman, McGraw-Hill, 1997, ISBN 0-07-0119 38-4.

- Fortran 90 Programming - Ellis, Philips, Lahey, Addison Wesley, Wokingham, 1994, ISBN 0201-54446-6. (*)

- Fortran 95 - Counihan, UCL, 1997, 1857283678.

- Fortran 95 Handbook - Adams, Brainerd, Martin, Smith and Wagener, MIT, 1997, ISBN 0-26251096-0.

- Fortran 95 Language Guide - Gehrke, Springer, London, 1996, ISBN 3-540-76062-8.

- Introducing Fortran 90 - Chivers and Sleightholme, Springer-Verlag London, 1995, ISBN 3540-19940-3. (*)

- Introduction to Fortran 90/95 - Chapman, McGraw-Hill, 1997, ISBN 0-07-011969-4.

- Introduction to Fortran 90/95, Algorithms, and Structured Programming, Part 1: Introduction to Fortran 90, Part 2: Algorithms and Fortran 90. R. Vowels: 93 Park Drive, Parkville 3052, Victoria, Australia (robin_v@bigpond.com). \$43 Aust with disk, ISBN 0-9596384-8-2.

- Introduction to Fortran 90 for Scientific Computing - Ortega, Saunders College Publishing, 1994, ISBN 0-030010198-0.

- Key Features of F - Adams, Brainerd, Martin and Smith, 1996, ISBN 0-9640135-2-5, Unicomp.

- Numerical Recipes in Fortran 90: The Art of Parallel Scientific Computing, Volume 2 of Fortran Numerical Recipes - Press, Teukolsky, Vetterling and Flannery, Cambridge U. Press, ISBN 0-521-57439-0, 1996. Code can be downloaded (purchased) from http://nr.harvard.edu/nr/store. A CDROM is also available (see Web site). (*)

- Problem solving with Fortran 90: for scientists and engineers - Brooks, 1997, Springer, 0-38798229-9. (*) 
- Programmer's Guide to F - Brainerd, Goldberg and Adams, 1996, ISBN 0-9640135-1-7, Unicomp.

- Programmer's Guide to Fortran 90, third edition - Brainerd, Goldberg and Adams, Springer, 1996, ISBN 0-387-94570-9. (*)

- Programming in F - Ellis and Philips, Addison Wesley, Wokingham, 1998, ISBN 0-201-179911.

- Programming in Fortran 90 - Morgan and Schonfelder, Alfred Waller/McGraw-Hill, Oxfordshire, 1993, ISBN 1-872474-06-3.

- Programming in Fortran 90 - I.M. Smith, Wiley, ISBN 0471-94185-9. (*)

- The DIGITAL Visual Fortran Programmer's Guide, ISBN 1-55558-218-4, April, 1999.

- The F Language Guide - Gehrke, Springer, London, 1997, ISBN 3-540-7615-9.

- The F Programming Language - Metcalf and Reid, Oxford University Press, 1996, ISBN 0$19-850026-2$, about $\$ 33$. This book is the definitive description of the $\mathrm{F}$ programming language - a carefully crafted subset of Fortran 90 that is highly regular and stripped of Fortran's older, dangerous features, but retains the powerful array language, data abstraction and pointers. It has six Appendices, including an extended example program that is available by ftp and solutions to exercises. Orders: www.oup-usa.org or toll free +1 800451 7556; UK: www.oup.co.uk.

- Upgrading to Fortran 90 - Redwine, SpringerVerlag, New York, 1995, ISBN 0-387-97995-6. (*)

Chinese:

- Programming Language Fortran 90 - He Xingui, Xu Zuyuan, Wu Qingbao and Chen Mingyuan, China Railway Publishing House, Beijing, ISBN 7-113-01788-6/TP.187, 1994.

\section{Dutch:}

- Fortran 90 - W.S. Brainerd, Ch.H. Goldberg, and J.C. Adams, translated by J.M. den Haan, Academic Service, 1991, ISBN 90-6233-722-8.

\section{Finnish:}

- Fortran 90 - Haataja, Rahola and Ruokolainen, Center for Scientific Computing (Finland), 1996, 286 pages, ISBN 952-9821-33-6. WWW version: http://www.csc.fi/oppaat/f90/.
French:

- Fortran 90; Approche par la Pratique - Lignelet, Série Informatique Éditions, Menton, 1993, ISBN 2-090615-01-4.

- Fortran 90. Les concepts fondamentaux, the translation of "Fortran 90 Explained" M. Metcalf, J. Reid, translated by M. Caillet and B. Pichon, AFNOR, Paris, ISBN 2-12-486513-7.

- Fortran 90; Initiation á partir du Fortran 77 - Aberti, Série Informatique Editions, Menton, 1992, ISBN 2-090615-00-6.

- Les spécificités du Fortran 90, Dubbesset, M. et Vignes, J., Éditions Technip, 1993, ISBN 2-71080652-5.

- Manuel complet du langage Fortran 90, et guide d'application, Lignelet, P., S.I. editions, Jan. 1995, ISBN 2-909615-02-2.

- Manuel Complet du Langage Fortran 90 et Fortran 95, Calcul intensif et Genie Logiciel, Lignelet, Masson Éditions, Paris, ISBN 2-225-85229-4.

- Programmer en Fortran 90, Delannoy, C., Eyrolles, 1992, ISBN 2-212-08723-3.

- Traitement des données numeriques avec Fortran 90, Olagnon M., Masson, 1996, ISBN 2-22585259-6.

- Savez-vous parler Fortran, AIN, M., Bibliothèque des universités (de Boeck), 1994. ISBN 2-80411755-3.

- Structures des données (et leurs algorithmes) en Fortran 90/95, P. Lignelet, Les Éditions Masson, Paris, ISBN 2-225-85373-8.

German:

- Fortran 90 Lehrbuch - Rabenstein, Hanser, 1995, ISBN 3-446-18235-7.

- Die Programmiersprache F - Gehrke, SpringerVerlag, ISBN 3-540-63376-6.

- Fortran 90 - B. Wojcieszynski and R. Wojcieszynski, Addison-Wesley, 1993, ISBN 3-89319600-5.

- Fortran 90: eine informelle Einführung - Heisterkamp, BI-Wissenschaftsverlag, 1991, ISBN 3411153-210.

- Fortran 90, Lehr- und Arbeitsbuch für das erfolgreiche Programmieren - W.S. Brainerd, C.H. Goldberg, and J.C. Adams, translated by P. Thomas and K. Paul, R. Olbenbourg Verlag, München, 1994, ISBN 3-486-22102-7.

- Fortran 90 Lehr- und Handbuch - T. Michel, BIWissenschaftsverlag, 1994.

- Fortran 90 Referenz-Handbuch: der neue FortranStandard - Gehrke, Carl Hansen Verlag, 1991, ISBN 3-446163-21-2. 
- Programmierung in Fortran 90 - Schobert, Oldenburg, 1991.

- Programmierung mit Fortran 90 - Bäumer, Vieweg, Braunschweig, 1997, ISBN 3-528-05208-2.

- Programmieren in Fortran - Erasmus Langer, Springer-Verlag, Wien, New York, 1993, ISBN 3211-82446-4, 0-387-82446-4.

- Software Entwicklung in Fortran 90 - Überhuber and Meditz, Springer-Verlag, 1993, ISBN 0-38782450-2.

\section{Japanese:}

- Fortran 90 Explained - Metcalf and Reid, translated by H. Nisimura, H. Wada, K. Nishimura, M. Takata, Kyoritsu Shuppan Co., Ltd., 1993, ISSN 0385-6984.

\section{Russian:}

- An Explanation of the Fortran 90 Programming Language (translation of Fortran 90 Explained Metcalf and Reid), translated P. Gorbounov, Mir, Moscow, 1995, ISBN 5-03-001426-8. Available also from Petr.Gorbounov@ cern.ch.

- FORTRAN 77 to Fortran 90 Tutorial - Einarsson and Shokin, Russian Academy of Sciences, Novosibirsk, 1995, ISBN 5-85826-013-6.

Swedish:

- Fortran 90 - en introduktion - Blom, Studentlitteratur, Lund, 1994, ISBN 91-44-47881-X.

\section{Where can I obtain courses, course material or consultancy?}

\section{Copyright but freely available course material is} available on the World Wide Web from the URLs:

- Paul Dubois's lecture notes and class materials on "Object Based Programming in Fortran 90" at ftp://ftp-icf.llnl.gov/pub/OBF90. (In WinZip, on the Options|Configuration menu, turn off "tar smart convert CR/LF".)

- Manchester Computer Centre: http://www.hpctec. mcc. ac.uk/hpctec/courses/ Fortran90/F90course. html or via ftp: ftp.mcc.ac.uk, in the directory /pub/mantec/Fortran90.

- U. of Liverpool: http://www.liv.ac.uk/HPC/ HPCpage.html - covers 190 and HPF, with Javaenhanced Web pages.

- CERN: http://wwwinfo.cern.ch/asdoc/f90.html or via anonymous ftp from asisftp.cern.ch in the directory $\mathrm{cnl}$ as the file f90tutor.ps.
- In French: Support de cours Fortran 90 IDRIS Corde \& Delouis (from http://www.idris.fr/data/cours/lang/f90).

- U. of Edinburgh (on HPF): Linkoping U.: http:// www.nsc.liu. se/f77to90.html.

- U. of New Mexico: ftp://mycroft.plk.af.mil/pub/ Fortran_90/Tutorial/.

Courses are available from:

- Walt Brainerd, a former member of J3, also on HPF (walt@fortran.com).

- Tom Lahey (sales@lahey.com).

- PSR (see above).

- Michael Metcalf, formerly of CERN, Switzerland, and an ex-member of J3 and WG5, offers a Fortran 90 course that lasts for six 75-minute sessions. There is an $\mathrm{F}$ version too. He is happy to negotiate holding either version anywhere in the world. These courses are suitable for graduates, or equivalent level, and are a useful way to "kick-start" a Fortran 90 or an F activity at a given site. Contact michaelmetcalf@compuserve.com, or Kärntner Ring 10, A-1010 Vienna, Austria (Tel.: +431 50379 40, Fax: +4315031145.

- John Reid, formerly of J3 and a member of WG5, offers a Fortran 90 course. He is happy to negotiate holding it anywhere in the world. It is suitable for graduates, or equivalent level, and is a useful way to "kick-start" a Fortran 90 activity at a given site. Contact J.Reid@letterbox.rl.ac.uk.

European companies offering courses and conversion consultancy are:

- The Computing Centre of Delft University of Technology organises courses on Fortran 90 elements for beginning programmers or an upgrade for Fortran 77 programmers. Courses can be given in English, Dutch, French, or German. See http://www.rc.tudelft.nl/cursus/ or info@RC.TUDelft.nl. Tel.: +31 15278 2000, Fax: +31 152783787 .

- IT Independent Training Limited, 2 Windlebrook Green, Bracknell, Berkshire, UK. Tel.: +44 1344 860172, Fax: +44 1344867992.

- Salford Software (see above).

- Simulog, attn. Mr. E. Plestan, 1 rue James Joule, F-78286 Guyancourt Cedex, France. Tel.: +33 1 30122780, Fax: +33 130122727 , info@simulog. fr, http://www.simulog.fr/US/html/prods/foresys. html, infos2i@cais.com, http://www. cais.net/s2i/ www/ general/foresys.html.

- Allgemeiner Software Service Prinz-Otto Str. 7c, D-85521 Ottobrunn, Germany. 
Tel.: +49 89 6083758, Fax: +49 8960851437 , alsos@compuserve.com, http://www.alsos.com.

A Japanese company offering courses and conversion consultancy is:

- SofTek Systems, Inc. (see above).

\section{Where can I find the Fortran and HPF standards?}

- The Fortran 95 standard document is available from ISO, and replaces Fortran 90. The document reference number is ISO/IEC 1539-1:1997. See http://www.iso.ch, or contact ISO Publications, 1 rue de Varembe, Case postale 56, CH-1211
Geneva 20, Switzerland. Fax: + 41227341079. It may also be obtained from national member bodies such as ANSI, 1430 Broadway, New York, NY 10018.

- The Fortran 95 standard is also available for online ordering in both electronic forms (ASCII, PostScript, and PDF) and printed form at http://www.fortran.com/fortran. The prices are set by ISO.

- A Russian translation of the old Fortran 90 standard (translator S.G.Drobyshevich) is available: Alla Gorelik (gorelik@applmat.msk.su).

- The HPF 2.0 document is available as ftp://softlib. rice.edu/ pub/HPF/hpf-v20.ps.gz. 

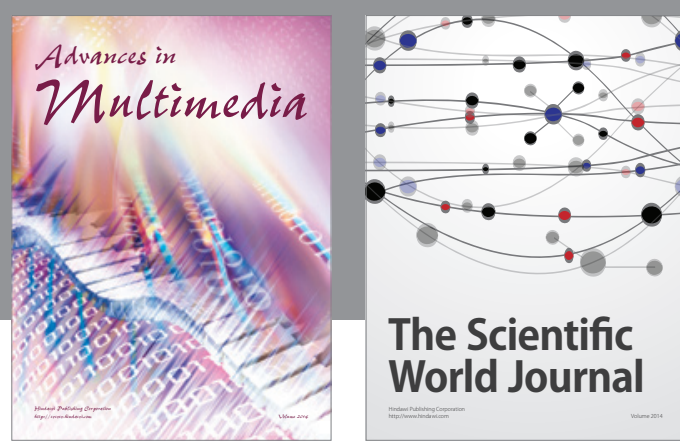

The Scientific World Journal
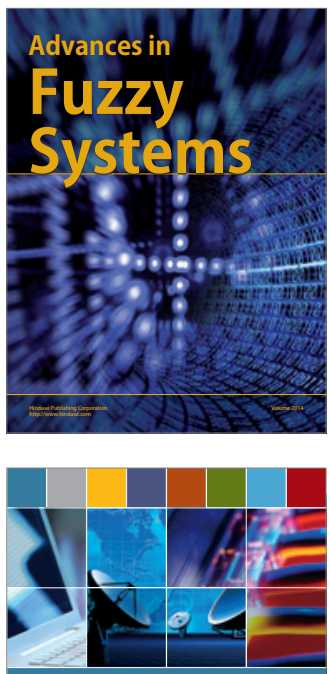

Computer Networks and Communications
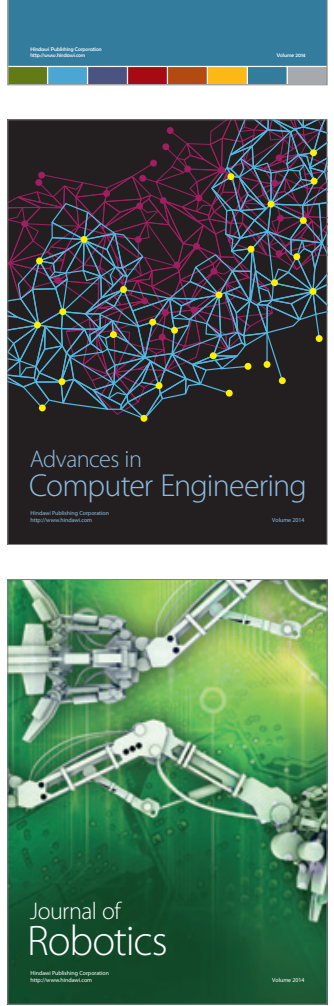
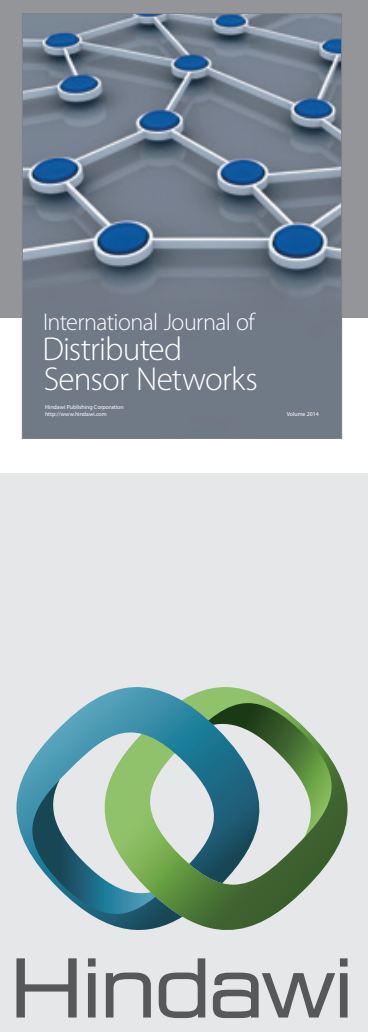

Submit your manuscripts at

http://www.hindawi.com
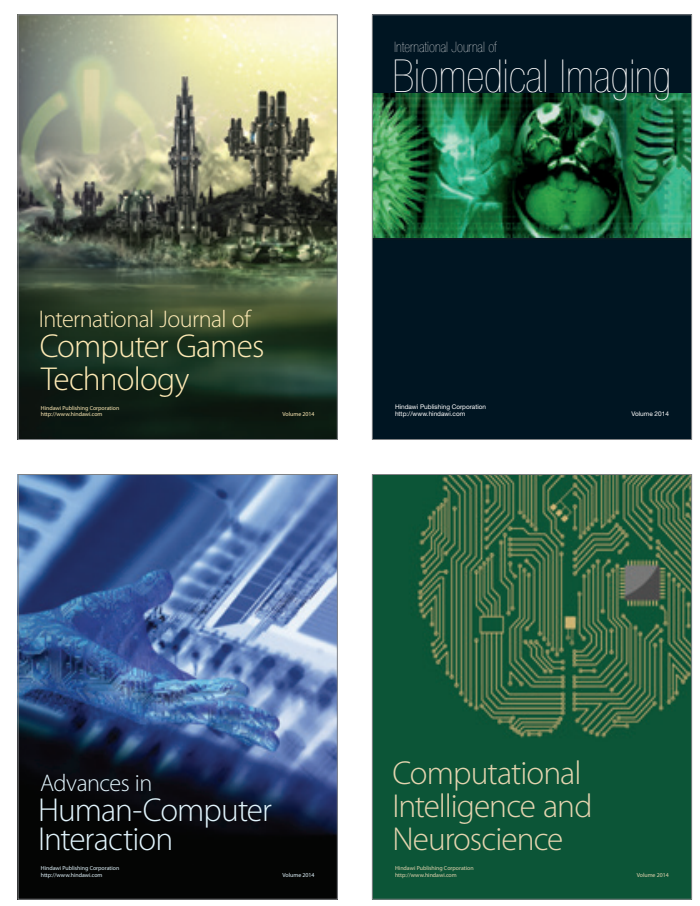
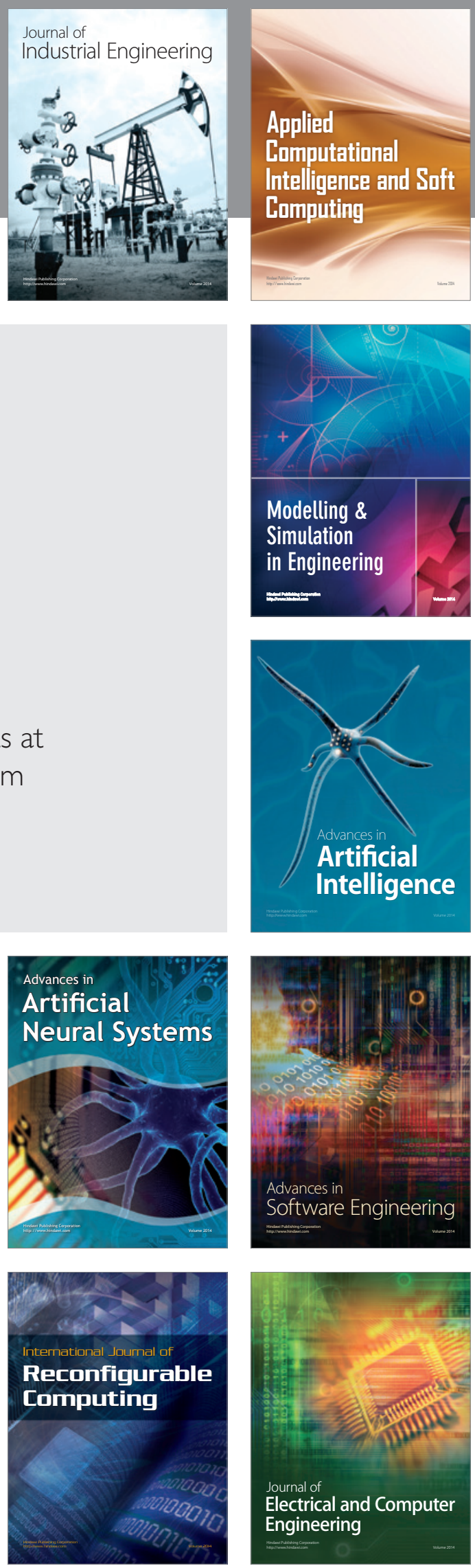